\title{
MÁRIO DE ANDRADE: trovador / domador da cidade
}

\section{Neilton Fonseca}

Desta cidade histórica, desta cidade completa,

Cheia de passado e presente, berço nobre onde nasci.

Meu pensamento é tal-e-qual São Paulo, é histórico e completo.

É presente e passado e dele nasce men ser verdadeiro...

(Momento)

No primeiro livro modernista de Mário de Andrade, Paulicéia Desvairada, o poema inicial já indica, desde o título, que a cidade de São Paulo é o seu motivo inspirador:

\section{INSPIRAÇÃO}

\author{
"Onde até na força do verão havia \\ empestades de ventos e frios de \\ crudelíssimo inverno".
}

Fr. Luís de Sousa

São Paulo! comoção de minha vida...

Os meus amores são flores feitas de original...

Arlequinal!...Trajes de losangos...Cinza e ouro...

Luz e bruma... Forno e inverno morno...

Elegâncias sutis sem escândalos, sem ciúmes...

Perfumes de Paris...Arys!

Bofetadas líricas no Trianon... Algodoal!...

São Paulo! comoção de minha vida...

Galicismo a berrar nos desertos da América! ${ }^{1}$ 
O poema é emblemático e paradoxal, como se observa já no sentido do título e na citação dos versos do poeta português Fr. Luís de Sousa. A cidade como inspiração é fato que situa o discurso poético na atualidade universal, em sintonia com a visão da matéria urbana como pedra de toque da lírica moderna. Com efeito, a cidade torna-se um dos motivos geradores centrais da nova poesia e locus simbólico da existência e da atuação do poeta. Da sua relação com o espaço urbano em que existe e circula como personalidade particular e artística motiva-se e se tece o texto poético numa relação tensionada entre a negatividade e a positividade. Do meio urbano onde o poeta existe e sobrevive, flui o canto possível que traduz as imagens da cidade inspiradora. Assim se configura a equação poética das metrópoles: as imagens urbanas somadas às vivências motivam e consubstanciam a inspiração do poema. O primeiro título de Paulicéia, portanto, confirma o compromisso de Mário: ser o poeta da grande metrópole dos trópicos, alargando os limites literários de nossa modernidade.

Os versos do poeta português sugerem o tom do discurso sobre a cidade inspiradora de Mário de Andrade. Os versos citados em pórtico compõem um jogo de sentidos opostos que se exprimem através da dissonância lexical dos termos, compondo a figura da antítese que se aproxima da condensação do oxímoro. ${ }^{2}$ A citação constitui um emblema das contradições que se tornam inerentes à visão da cidade por Mário de Andrade. Os versos assinalam um choque de climas. Numa primeira instância de sentido, poderiam ser entendidos no contexto da citação como uma alusão ao clima natural de São Paulo. A sugestão poética parte efetivamente dessa base semântica, mas para extrapolá-la de maneira sutil. Trata-se de um jogo de contrários, efetivamente, que se sintetiza num efeito a um só tempo retórico e poético, exprimindo o clima de choque entre tradição e modernização, apontando para síntese representada pela cidade.

Do ponto de vista da linguagem, o poema retoma a tradição literária que os versos citados representam e a coloca em choque com a modernização que Paulicéia anuncia. Aqui, na proposta de Paulicéia, como na cidade representada, o tempo moderno, ou seja, a modernidade, surge para reger o presente, a partir de uma sinalização da tradição que se estabelece como lastro e marco referencial. O contraste, portanto, é a imagem da forma, assim como é a forma da síntese pela qual a cidade é figurada na percepção do poeta. Analogicamente à comoção de Baudelaire diante de sua Paris em transformação, Mário comove-se com as imagens urbanas que observa e vivencia. Em sua Paris modernizada, Baudelaire vivencia o choque diante das transformações da vida urbana e, como um esgrimista, busca as palavras e os versos adequados para 
exprimir essa experiência em sua poesia. ${ }^{3}$ Mário de Andrade, no seu próprio tempo e lugar, constata as transformações paulistanas e vivencia, a seu modo, o impacto do choque do poeta moderno. O poeta brasileiro também se propõe a exprimir as novas imagens urbanas sob o crivo e o cruzamento de sensações e sentimentos novos e antigos, através de uma linguagem consoante com os novos tempos. ${ }^{4}$

Para Mário de Andrade, São Paulo é o espasmo, a comoção, um clima de contrários, como lugar em que se põem em marcha os processos de modernização em choque com as tradições. Dessa forma, como inspiração do processo modernizador, do qual os poemas são a concretização em linguagem, a cidade é erigida a símbolo da renovação literária. Do nome da cidade deriva o título Paulicéia, primeiro livro de poesia modernista, abarcando substantiva e adjetivamente o seu nome e seu desvario modernizante. São Paulo é tomado como cidade-inspiração, como imagens que se refletem no jogo de espelhos da representação poética. Ao assumir a feição de metrópole, torna-se o chão histórico da nossa modernidade, oferecendo as condições para o desenvolvimento do modernismo nascente, em confronto aberto com os remanescentes passadistas. Como locus da modernidade, inclusive na vida literária, a cidade se converte em inspiração do poeta, assim como o é da própria renovação literária que abriga e patrocina.

Nos anos vinte a cidade de São Paulo encontrava-se em acentuado processo de modernização, tornando-se cada vez mais complexa, definindo-se pelo choque entre o passado que resiste e o novo que surge desvairadamente. Se hoje o termo parece excessivo para a verdadeira marcha de nosso processo de modernização, efetivamente em descompasso com os grandes centros urbanos mundiais, no entanto representa a medida que o poeta quis lhe dar, como sujeito observador daquele momento histórico. Dessa forma, o exagero que muitas vezes se tem apontado e criticado não pode ser visto como simples defeito da forma ou arroubo de modernista de primeiro momento, mas como atitude conscientemente programática, uma vez que a idéia de modernidade surge, através do seu texto instaurador, fortalecida e superestimada. Mário de Andrade, mais do que constatador, é um fundador visionário do discurso lírico sobre a vida urbana, pois prevê e projeta em imagens poéticas o turbilhão em que a cidade paulista vai se transformar definitivamente algumas décadas mais tarde. Sua atitude, portanto, é também prospectiva, adiantando a complexidade de um quadro que o futuro próximo viria definir com clareza, pondo a vida e experiências urbanas em contínuo debate. 
A visão do novo não é pacífica, pois a perspectiva do eu poético é perpassada pela experiência de vida do sujeito-cidadão que a assume. Diante da cidade que se transforma através do processo de urbanização e de expansão econômica e industrial, a nova realidade se impõe frente à anterior vivenciada pelo poeta e impressa em sua lembrança e em seu sentimento, gerando um torvelinho de contrastes e contradições captado e expresso em imagens, juízos e comentários que enformam os poemas. Em "Inspiração", observa-se que a menção ao nome da cidade se faz através de uma exclamação e em seguida registra-se o estado de espírito que é nomeado de comoção. Entretanto, no discurso poético a cidade não é apenas a causa, pois se transmuda no próprio estado psicológico dessa comoção, e assim é interiorizada pelo eu lírico. Depois de exclamar: "São Paulo! comoção da minha vida...", o poeta finaliza o verso com reticências para indicar o prolongamento de efeito que provém da interiorização do objeto de sua contemplação. Este tom de enternecimento dos versos que registram impressões fortes e perpassadas de sentimento em relação à cidade repetem-se em outros poemas, em que a estrutura frasal desenvolve-se afunilando para o fecho em ponto de exclamação e reticências. Os versos se exprimem em frases que mantêm independência sintática mas expressam as golfadas de uma emoção contínua que se avoluma em crescente, encontrando seu arremate no verso final do poema, muitas vezes colocada em estrofe espacialmente destacada.

Nos poemas de Paulicéia, geralmente os aspectos que caracterizam a cidade são versados em frases nominais, como dados pinçados de um conjunto que se exprimem sem relação orgânica entre si. Como objetos captados por um olhar direcionado, cada aspecto é tomado como recorte, em separado, o que potencializa o seu efeito no mosaico urbano de pedaços coloridos que se justapõem. Dessa maneira, a forma do poema iconiza a imagem da cidade que se apresenta arlequinal, em trajes de losango, pedaços cinza e ouro justapostos, homóloga à condição de Arlequim assumida pelo eu lírico. A condição arlequinal é, portanto, uma máscara representativa de sua persona moderna que, como assinala João Luiz Lafetá, corresponde à primeira fase da poesia de Mário:

À preocupação cosmopolita, que sucede às grandes transformações urbanas do começo do século, corresponde a fase vanguardista, a máscara do trovador arlequinal, do poeta sentimental e zombeteiro que encarna o espírito da modernidade e de suas contradições. ${ }^{5}$ 
A interiorização da cidade como objeto da contemplação aprofunda-se no segundo poema, quando os sentimentos afloram ao primeiro plano do discurso. Nesse texto, o poeta assume a condição de trovador, sinalizando sua relação com a cidade através da mediação dos sentimentos:

\section{O TROVADOR}

Sentimentos em mim do asperamente

dos homens das primeiras eras...

As primaveras de sarcasmo

intermitentemente no meu coração arlequinal...

Intermitentemente...

Outras vezes é um doente, um frio

na minha alma doente como um longo som redondo...

Cantabona! Cantabona!

Dlorom...

Sou um tupi tangendo um alaúde! (PD, p. 83)

Enquanto no primeiro texto o poeta afirma claramente que a cidade é a fonte de sua inspiração, o que implica num compromisso com uma expressão figurativa da vida urbana, neste segundo ele adiciona a isso a sua posição de homem condicionado cultural e historicamente. Moderno, porém datado e dono de uma experiência anterior, é a condição do homem presente que vive o processo de transformações do mundo. E as imagens da tradição podem ser varridas das ruas e das fachadas, como bem assinalou Baudelaire, mas não das consciências dos que observam criticamente as transformações em que se inserem inapelavelmente, inclusive como sujeitos. Mário assume-se como um trovador da cidade. Em sentido histórico, o trovador é um sujeito cultural que remonta à tradição literária medieval. Era o poeta que compunha versos e melodias e os executava ao som de seu instrumento. Sua missão fundamental era representar a vida sensível da sua comunidade através da poesia e do canto. A atuação do trovador tinha alto sentido comunitário e como tal estava inserida funcionalmente na vida social. No entanto, o trovador moderno representa a vida da cidade através de um canto que não consegue mais ser comunitário no sentido antigo. Nos tempos modernos, a cidade não se confunde mais com a idéia original de comunidade. Então, o poeta questiona sua condição de trovador que, na época atual, é um 
indivíduo espremido e encalacrado entre o lastro do passado, que sustenta a tradição, e o desafio da modernidade, a ruptura que instaura o novo. A cidade se transforma e o poeta se move nesse espaço de contradição, na vivência do choque da vida moderna com a bagagem cultural do passado. Esta situação torna os seus sentimentos instáveis, como "primaveras de sarcasmos no seu coração arlequinal", frente ao processo a que assiste e que apresenta em sua poesia. Em suma, alavancado pela contemplação da cidade que o inspira, os seus sentimentos fluem contraditórios como se traduzem nos seus versos. Esta contradição se firma como eixo gerador do discurso e é percebida como índice de um incômodo interior que se traduz pela confirmação de que a alma moderna, semelhante a do poeta, é "doente". Ter essa "doença" significa metaforicamente o sentir contraditoriamente as coisas, pulsão que aflora como força criativa e ribomba no seu eu, "como um longo som redondo..." O poema registra a consciência de que o sentimento é uma força primordial inerente à condição do ser humano, elo que nos liga aos "homens das primeiras eras" e cuja subsunção pela racionalidade moderna é um incômodo sentido como uma doença. ${ }^{6}$ A consciência martela e o poeta sente, como trovador que introjeta o assunto para melhor exprimi-lo, o toque intermitente da inspiração que o compele a cantar contraditoriamente a cidade. $\mathrm{O}$ verso final é o corolário desse seu estado de espírito, por isso está em destaque estrófico, conformando a inquietude resultante da amálgama cultural problemática de que sua consciência histórica é formada: "Sou um tupi tangendo um alaúde!"

Mário faz questão de definir a sua subjetividade dessa maneira, apresentandose como homem brasileiro partícipe de uma cultura que tem raízes ameríndias somadas à bagagem da tradição européia transplantada. No poema, o alaúde, instrumento bastante utilizado pelos europeus medievais, é o símbolo por excelência da tradição cultural mais antiga dos povos colonizadores. Já o denominativo "tupi” indica a condição original ameríndia. Esse jogo de linguagem representa a busca de identidade do próprio eu lírico e da cidade que ele tematiza. ${ }^{7}$ Assim, as marcas de uma identidade cultural instável, porque ainda não tem seus componentes díspares completamente amalgamados, pontuam o seu discurso poético e com isso potencializam os efeitos das contradições nos poemas.

De saída, Mário assume claramente a condição de autor de um discurso que é relativo a um determinado lugar, a cidade de São Paulo. Conseqüentemente, a cidade entra na própria constituição de uma poética urbana que incorpora sua geografia, sua história, seus valores, sua linguagem e suas contingências cosmopolitas como elementos integrantes da linguagem que a traduz. ${ }^{8}$ Essa precupação é constante na 
poesia de Mário, que reiteradamente se define cultural e textualmente como um poeta brasileiro mas, sobretudo, paulistano.

Os dois primeiros poemas de Paulicéia Desvairada situam a condição que o sujeito da enunciação assume, a partir de um chão histórico, geográfico e cultural. Depois de fincar a baliza fundamental, a partir da tomada da cidade como motivo inspirador, Mário procura situar-se nas três dimensões em que o seu livro se insere como contribuição estética. A dimensão temporal é a modernidade, no seu processo de instauração na vida artística brasileira, que assume tom prevalente e fundadora nos poemas. A dimensão espacial é a cidade de São Paulo, como locus central da modernização do País, que se torna centro de nosso contato com o mundo. A dimensão cultural, por sua vez, é decorrente da inserção do sujeito no espaço histórico-geográfico de um país latino, ex-colônia européia e ainda dependente política e economicamente, cuja identidade encontra-se ainda instável e problemática. ${ }^{9}$

A multiplicação das vozes líricas é uma das marcas da modernidade que se traduz pela dispersão do eu no discurso poético. O poeta moderno detém uma subjetividade plural, que não se confunde necessariamente com a do seu ser individual empírico. Benjamin aponta que, para Baudelaire, "o poeta goza o iningualável privilégio de poder ser, conforme queira, ele mesmo ou qualquer outro". ${ }^{10}$ No poeta português Mário de Sá-Carneiro, a dispersão do eu lírico confunde-se com a crise de personalidade do eu empírico. Já Fernando Pessoa soube dar vazão à sua sensibilidade dispersa, aguçando a consciência das suas várias vozes que se multiplicam em heterônimos. ${ }^{11}$ Em Mário, essa condição do poeta moderno está representada pela figura do trovador que é a arqui-imagem do eu lírico, emblema de um arsenal de máscaras ou personae, capaz de se multiplicar em diversos "eus” nas várias enunciações, como o próprio poeta registrou:

Eu sou trezentos, sou trezentos-e-cincoenta,

As sensações renascem de si mesmas sem repouso (RM, p. 211)

Essa multiplicação representa uma busca de abarcar os diferentes pontos de vista e as diversas formas capazes de expressar as próprias sensações dispersas no mundo moderno. Mas o trovador tem consciência da tradição em que se insere e exibe o domínio do seu instrumento:

Abraço no meu leito as milhores palavras, E os suspiros que dou são violinos alheios; 
Eu piso a terra como quem descobre a furto

Nas esquinas, nos táxis, nas camarinhas seus próprios beijos! (RM, p. 211)

A dispersão e a inquietação da voz criadora é a condição necessária do trovador moderno, ao se tornar um cantor da urbe complexa em constante movimentação. Mas em nenhum momento o poeta abdica de buscar a essência de sua individualidade de artista:

Eu sou trezentos, sou trezentos-e-cincoenta, Mas um dia afinal eu toparei comigo...

Tenhamos paciência, andorinhas curtas,

Só o esquecimento é que condensa,

E então minha alma servirá de abrigo. (RM, p. 211)

A imagem do trovador como alter ego cultural do poeta atravessa a poética de Mário de Andrade indo ecoar também na abertura da Lira Paulistana. A viola é a imagem inseparável que é contígua à adoção da poesia como forma de participar da construção da cidade no plano artístico e simbólico. A experiência de vida do trovador é compartilhada com a viola que se torna sujeito solidário na vivência das vicissitudes cotidianas. O desencanto final do trovador perante a cidade que seu canto não consegue humanizar corresponde à ruína física de sua viola. O encanto do poeta para com a cidade é substituído pela angústia do olhar crítico. Os seus versos registram uma tomada definitiva de consciência quanto ao seu desconcerto. O canto se torna impossível, equivalendo, no plano da criação poética, a uma perda do instrumento, metaforizada pela fato de que a viola está quebrada:

Minha viola quebrada

Raiva, anseios, lutas, vida,

Miséria, tudo passou-se

Em São Paulo. (LP, p. 351)

A imagem do trovador é problemática porque se estabelece nos limites de uma identidade cultural que se encontra ainda indefinida. O canto do trovador não é mais capaz de encantar a cidade, cuja sensibilidade se encontra embotada pelos barulhos de seu corpo em constante recomposição. Em Paulicéia Desvairada, o eu arlequinal 
providencia uma imagem de reforço representada pelo domador. A figura do domador assume um sentido muito especial no encontro da cidade observada com o discurso poético que a representa. Eis como a imagem se atualiza no poema:

\section{O DOMADOR}

Alturas da Avenida. Bonde 3.

Asfaltos. Vastos, altos repuxos de poeira sob o arlequinal do céu ouro-rosa-verde...

As sujidades implexas do urbanismo.

Filets de manuelino. Calvícies de Pensilvânia.

Gritos de goticismo.

$\mathrm{Na}$ frente o tram da irrigação,

Onde um sol bruxo se dispersa

Num triunfo persa de esmeraldas, topázios e rubis...

Lânguidos boticellis a ler Henry Bordeaux

Nas clausuras sem dragões dos torreões...

Mário, paga os duzentos réis.

São cinco no banco: um branco, um noite, um ouro, um cinzento de tísica e Mário...

Solicitudes! Solicitudes!

Mas...olhai, oh meus olhos saudosos dos ontens

Esse espetáculo encantado da Avenida!

Revivei, oh gaúchos paulistas ancestremente!

E oh cavalos de cólera sangüínea!

Laranja da China, laranja da China, laranja da China

Abacate, cambucá e tangerina!

Guardate! Aos aplausos do esfusiante clown,

Heróico sucessor da raça heril dos bandeirantes, Passa galhardo um filho de imigrante,

Louramente domando um automóvel! (PD, p. 92) 
Há neste poema uma questão interessante que se enuncia já no seu título. O cenário e o ângulo de observação são, como sempre, a cidade em sua movimentação cotidiana, destacada através de quadros particulares. Na primeira estrofe não há sequer um verbo. O poeta observa com o olhar fixo, congela as imagens e destaca os aspectos representativos em frases nominais. Estes elementos expoem "as sujidades implexas do urbanismo" compondo um quadro que tem como fundo a poeira e o asfalto. A viagem de bonde prossegue e os verbos surgem para registrar os detalhes da movimentação urbana observada e, em seguida, para indicar os gestos que o poeta recomenda a si mesmo. Nesse momento, numa projeção especular, o eu lírico vê a si mesmo na imagem da cidade e vice-versa. Ele reconhece sua necessidade de inserção na engrenagem cotidiana, em conformidade com a etiqueta social, mas não sem fazer uma auto-ironia: "Mário, paga os duzentos réis".

Nessa auto-invocação encontra-se embutida uma dúvida zombeteira, uma vacilação da vontade, que significa um questionamento tácito quanto à sujeição gentil do indivíduo às normas do sistema. Pagar a passagem e acomodar-se entre homens estranhos, no bonde certamente lotado, é um dever que se impõe à gente de bem, requerendo a postura amena e educada que se traduz pelas solicitudes. Para assumir essa posição de conformidade social, solicitude e urbanidade, é preciso tornar-se o domador de si mesmo e honrar o compromisso social. Mas não sem ironia, e com um certo sarcasmo até, que se registra na dupla exclamação do verso: “Solicitudes! Solicitudes!".

No caso, a tensão posta no texto não se dilui pela simples aceitação, mas apenas se relativiza uma vez mediada pela ironia com que o poeta encara a situação prosaica. Esta é uma postura arlequinal também, como outras em que a consciência do eu lírico lhe aconselha: “ - Mário, põe a máscara!”. Pode ser conveniente, em termos, conservar-se ajustado às convenções e às etiquetas sociais, mas desde que a consciência crítica se mantenha em alerta.

$\mathrm{Na}$ estrofe seguinte, a autocontemplação cede à visão exterior de um fato que merece versos exclamativos. O poema, que começa estático com a visão dos objetos da paisagem urbana, de chofre torna-se dinâmico. E o dinamismo provém da presença marcante do automóvel. A isso somam-se os ruídos da avenida, com os pregões dos vendedores, a exclamação dos que observam, o aplauso do clown, os elementos evocados para a composição do cenário. A visão da máquina automotiva constitui "o espetáculo encantado da avenida" que é preciso ensinar os olhos a ver. Sutilmente se esclarece a "saudade dos ontens" impressa no olhar que contempla a cidade presente, em busca de ver sobre seu desenho a figura estática da cidade do passado. Do passado 
provêm a experiência e o saber registrados na memória que ainda governam e direcionam os critérios com que o presente inicialmente é visto e avaliado pelo sujeito urbano. Em contrapartida, há o compromisso com a valorização do moderno, ao menos no que apresenta de positivo. Por isso, é preciso ensinar os olhos a verem e os versos a traduzirem o tempo presente da cidade. O automóvel tira o poeta de uma espécie de letargia em via pública devido ao aguçamento da atenção que causa com sua presença. Ora, o automóvel era símbolo por excelência da modernidade, do progresso e da velocidade, desde os anos finais do século XIX. Como tal, foi exaustivamente cantado em prosa e verso antes mesmo das vanguardas, sendo um dos motivos recorrentes dos textos fundadores da modernidade. ${ }^{12}$ No poema de Mário, um objeto estético moderno de valor universal é perfeitamente enquadrado no espaço particular da metrópole paulista. A visão acerca do automóvel é francamente positiva, como objeto que representa a força do progresso de São Paulo, domado pelo pulso do filho de imigrante, protótipo do homem paulistano moderno. Se o bandeirante foi o domador dos caminhos selvagens no passado, rasgando os rios em busca de riquezas e prosperidade, o migrante agora o sucede dominando a máquina e as avenidas por onde caminham, ou melhor, trafegam na direção dos novos tempos, igualmente em busca de riqueza e prosperidade. Disso depreende-se analogicamente que o progresso é a força que impulsiona a urbe, enquanto o paulistano é visto como seu legítimo domador.

Essa imagem é reiterada no poema VII de Losango Cáqui, quando o domador recebe o aplauso legitimador da cidade, no contexto urbano que é justaposto à moldura da natureza de forma plástica e harmônica:

\author{
E Paulicéia em frente \\ Recostada no espigão do horizonte \\ Aplaude o domador doiradamente \\ Batendo a mão do Sol na mão da Terra. (LC, p.130)
}

O sentido poético de domador é realmente expressivo e fecundo na poesia de Mário de Andrade e sugere a formulação de uma hipótese explicativa ainda mais abrangente. No poema anterior, o eu lírico se apresenta, já no título, como "O Trovador" que se dispõe a operar um discurso, um canto sobre a cidade. Assim como o paulistano moderno se manifesta "louramente domando um automóvel", o poeta, ele também um paulistano moderno, com sua percepção expressa através de linguagem e estética novas, se apresenta diante da cidade que se torna "selvagem" pela moderni- 
zação, como seu domador. Pode-se ver aqui uma metáfora da nova condição do poeta no mundo moderno. Domar significa dominar os impulsos, conduzir os movimentos a uma ordem. Em última análise, domar significa submeter a uma forma e a uma linguagem. O automóvel representa a força moderna condensada num motor que é medida em cavalos de potência. E essa força é domada pelo pulso de quem o comanda e dá uma forma ao seu movimento, mediante uma linguagem técnica que na prática se exprime através da habilidade de dirigir. O seu motor é acionado pelos cavalos de potência e precisa ser domado para funcionar segundo as determinações e necessidades de quem o conduz. Assim, constitui um símbolo da cidade que se encontra numa corrida veloz para a modernização. Analogicamente, a cidade moderna é essa força desvairada que precisa ser domada, submetida de novo à uma forma e uma linguagem, para funcionar segundo as aspirações do homem. Dessa maneira, exprimir a cidade em versos significa domá-la, pô-la nas rédeas da linguagem, de novo humanizála, tornando-a inteligível, transparente ao sentimento humano. Se o desafio do homem moderno é, como domador, dominar a técnica pondo sua força extraordinária a serviço da humanidade, o desafio do poeta é exatamente o de tentar dar expressão à cidade, humanizando-a ao torná-la novamente um espaço poético, segundo uma nova concepção de poesia. A cidade que o poeta tem diante de si é desvairada e sua força bestial origina-se do ritmo do progresso e das transformações. Dessa forma, Mário, poeta urbano, assume-se como o seu domador, através da linguagem poética que ele fundamenta como Desvairismo. Seu objetivo é desentranhar das vivências urbanas os temas poéticos da cidade, dar-lhe uma forma estética, humanizando-a através da representação artística.

O poeta tem plena consciência das limitações e da mesquinhez da realidade que ele utiliza como matéria de poesia. Sobre os temas e assuntos colhidos nas andanças, através da experiência de viver e de sentir a cidade, ele faz a transmutação poética, tocando a matéria-prima com os seus sentidos de artista sensível. Essa posição se torna inequivocamente clara num trecho do poema "Carnaval carioca", do livro Clã do Jaboti:

Ânsia heróica dos meus sentidos

Pra acordar o segredo de seres e coisas.

Eu colho nos dedos as rédeas que param o infrene das vidas,

Sou o compasso que une todos os compassos

E com a magia dos meus versos

Criando ambientes longínquos e piedosos 
Transporto em realidades superiores

A mesquinhez da realidade.

Eu bailo em poemas, multicolorido!

Palhaço! Mago! Louco! Juiz! Criancinha!

Sou dançarino brasileiro!

Sou dançarino e danço! E nos meus passos conscientes

Glorifico a verdade das coisas existentes

Fixando os ecos e as miragens.

Sou um tupi tangendo um alaúde

E a trágica mixórdia dos fenômenos terrestres

Eu celestizo em euritmias soberanas,

Ôh encantamento da Poesia imortal!... (CJ, p. 165-6)

O trecho do poema encerra uma profissão de fé em que Mário assume a poesia como uma missão visceral. No verso seguinte o poeta indaga:

Onde que andou minha missão de poeta, Carnaval?

Os passos do artista são conscientes no desempenho dessa missão. Nesse sentido, a sua posição assemelha-se àquela que Benjamim atribui a Baudelaire. ${ }^{13}$ Em seu poema, o poeta brasileiro se apresenta como o elo que une todos os compassos através da subjetividade múltipla que encarna as personae da cultura em fase de estabelecimento de uma identidade ou de um caráter que ora se define pela indefinição, que se caracteriza por não se ter definido ainda o seu caráter específico. ${ }^{14} \mathrm{O}$ trovador é o tupi que se mune do alaúde para transformar a realidade com a magia dos seus versos. É o arlequim que dança com as palavras num ritual metafórico para glorificar e celestializar a realidade. Sua dança é cifrada nos versos que repõem a função primordial do poeta "acordar os segredos das coisas e seres". Dessa forma, o trovador doma a mesquinhez da realidade que transmuta em ecos e miragens através do encantamento da poesia.

A equação trovador/domador articula e unifica a dupla função que o poeta assume como missão diante da cidade/sociedade. As palavras têm o sentido metafórico reforçado a tal ponto que se tornam alegóricas. Assim, o sentido de trovador, aquele que doma as palavras, pondo-as nas rédeas de uma linguagem ordenada, de onde se pode extrair uma força expressiva, funde-se com o sentido de domador, aquele que submete uma força bruta às rédeas de uma ordem, de uma linguagem. Pode-se arriscar ainda uma extensão explicativa a partir da própria composição dessas 
palavras. O poeta trova e, assim fazendo, doma a sua dor, que é a dor da cidade, no discurso de sua poesia. ${ }^{15}$ Diante da profusão de imagens novas que ferem suas retinas sensíveis, ele opera com as palavras e a forma para domar e exprimir o corpo da cidade. Eis a missão que o poeta insofrido assume na engrenagem urbana: trovar/ domar a dor, em suas dimensões de prazer e sofrimento, utopia e realidade, assumindo a condição de homem e artista inserido na engrenagem da vida moderna.

\section{$\operatorname{son}$}

\section{NOTAS}

${ }^{1}$ Cf. ANDRADE, Mário de. Poesias completas, p. 83. Daqui em diante, na citação de poema ou fragmento serão indicadas as iniciais do livro a que pertence, seguidas do número da página em que consta na edição crítica das poesias completas do autor. As iniciais utilizadas são: (PD) Paulicéia Desvairada, (LC) Losango Cáqui, (CJ) Clã do Jabuti, (RM) Remate de Males, e (LP). ANDRADE, Mário de. Poesias Completas. Edição crítica de Diléa Zanotto Manfio. Belo Horizonte: Itatiaia; São Paulo: EDUSP, 1987.

${ }^{2}$ Hugo Friedrich comenta a respeito de Baudelaire: "Esta aproximação do que normalmente é incompatível chama-se oxymoron. É uma antiga figura do discurso poético, apropriada para exprimir estados complexos da alma. Em Baudelaire sobressai por seu emprego desmedido. É a figura chave de sua dissonância fundamental." Cf. FRIEDRICH, Hugo. Estrutura da lírica moderna. São Paulo: Duas Cidades, 178, p. 46.

${ }^{3}$ A respeito Benjamin afirma: "A experiência do choque é uma das que se tornaram determinantes para a estrutura de Baudelaire." Cf. BENJAMIN, Walter. "Sobre alguns temas em Baudelaire.” In:-. Charles Baudelaire: Um lírico no auge do capitalismo. Obras escolhidas III. 3.ed. São Paulo: Brasiliense, 1994. p. 112.

${ }^{4}$ Como observa João Luiz Lafetá, é da vivência do choque "que nascem os poemas novos de Paulicéia Desvairada, lirismo complexo de um ambiente hostil do qual o poeta tenta extrair a cara, desenhandoa a golpes de sons chocantes, hipérboles, metáforas duvidosas, identificações muito rápidas, naufrágios, alucinações." Cf. LAFETÁ, João Luiz. Op. cit., p. 17.

${ }^{5}$ Cf. LAFETÁ, João Luiz. Op. cit. p. 15.

${ }^{6}$ A questão faz lembrar a postura do heterônimo pessoano Alberto Caeiro, poeta das sensações e da natureza que recusa a racionalidade, a modernidade urbana e a reflexão sobre o mundo, preocupações que seriam sintomas de uma "doença". Diz o poeta, no poema III de O guardador de Rebanhos: "O mundo não se fez para pensarmos nele/ (Pensar é estar doente dos olhos)"E adiante, no poema V: "Que penso eu do mundo? / Sei lá o que penso do mundo! / Se eu adoecesse pensaria nisso." Cf. PESSOA, Fernando. Obra poética. Rio de Janeiro: Nova Aguilar, 1986, p. 139-140.

${ }^{7}$ João Luiz Lafetá acentuou essa questão em seu estudo, mostrando que a máscara do trovador arlequinal constitui a "pesquisa de identidade do poeta e de sua Paulicéia cosmopolita". Cf. Op. cit., p. 16-7.

${ }^{8}$ Eduardo Hoornaert comenta "que não existe discurso senão situado", pois "o lugar entra na própria constituição do discurso proferido pelo homem." Cf. HOORNAERT, Eduardo et al. História da igreja no Brasil. Petrópolis: Vozes; São Paulo: Edições Paulinas, 1983, t. II/1, p. 142.

${ }^{9}$ Essa foi uma preocupação fundamental do autor, como atestam o seu livro Macunaíma, de 1928, e os seus estudos de música, folclore e cultura brasileira em geral.

${ }^{10}$ Cf. BENJAMIM, Walter. Op. cit., p. 52. 
${ }^{11}$ Em Mário de Sá-Carneiro (1890-1916) a dispersão do eu lírico torna-se leitmotiv de sua poesia, como se pode constatar no livro de poemas Dispersão, e confunde-se com a psicologia pessoal do artista, que acabou cometendo suicídio. Fernando Pessoa (1888-1935) conseguiu racionalizar o processo, multiplicando-se em várias outras vozes, originando heterônimos como Álvaro de Campos, Ricardo Reis e Alberto Caeiro. Na história de vida de Mário de Andrade também constam profundas crises de depressão e até a idéia de morte, como o autor esclarece numa de suas cartas: "estava mesmo perseguido pela idéia do suicídio, quando a criação do Departamento de Cultura me salvou". Cf. "Correspondência". In: LAFETÁ, João Luiz. Mário de Andrade. São Paulo: Abril Educação, 1982, p. 94.

${ }^{12}$ Cf. BERMAN, Marshall. Tudo que é sólido desmancha no ar. São Paulo: Companhia das Letras, 1986.

${ }^{13}$ Eis a afirmação de Benjamin: "A produção poética de Baudelaire está associada a uma missão. Ele entreviu espaços vazios nos quais inseriu sua poesia. Sua obra não só se permite caracterizar como histórica, da mesma forma que qualquer outra, mas também pretendia ser e se entendia como tal." Cf. BENJAMIN, Walter. Op. cit., p. 110.

${ }^{14}$ Vide o personagem Macunaíma, o herói sem nenhum caráter, emblema do homem brasileiro, na visão de Mário de Andrade.

${ }^{15}$ Telê Ancona Lopez afirma: "Ser trovador significa também arcar com os sofrimentos que vêm do culto de sua dama, sua senhora. Para Mário, a dama escolhida é a cidade, particularizada em um momento da humanidade, vivido em seu país." Cf. LOPEZ, Telê Ancona. "Arlequim e modernidade". In: - . Mariodeandradiando. São Paulo: HUCITEC, 1996, p. 31. trovador / domador da cidade. Légua \& meia: Revista de

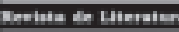
literatura e diversidade cultural. Feira de Santana: UEFS, n¹, 2002, p. 237-251.

Aleilton Santana da Fonseca é Professor da Universidade Estadual de Feira de Santana. Licenciado em Letras Vernáculas pela UFBA, Mestre em Letras pela UFPB e Doutor em Letras pela USP. Publicou: Enredo romântico, música ao fundo: Manifestações lúdico-musicais no romance urbano do Romantismo (1996), Ján dos Bois e outros contos (1997), Rotas e imagens: Literatura e outras viagens (co-organizador, 2000), O desterro dos mortos (contos, 2001). É co-editor de Iararana, Revista de arte, crítica e literatura; e editor de Légua \& meia. Membro do conselho editorial do Selo Letras da Bahia (FUNCEB), do conselho editorial de Agere (UFBA) e de Politeia (UESB). 